\title{
Comparison of New Generation Sequencing (NGS), nCounter and Quantitative PCR (qPCR) Technologies for the Detection of METExon 14 Skipping Mutations
}

\author{
Martínez $\mathbf{S}^{1}$ and Tornador $\mathbf{C}^{1,2,3 *}$ \\ ${ }^{1}$ Teresa Moretó Foundation, C. Verge de Guadalupe 18, Esplugas de Llobregat, Spain \\ ${ }^{2}$ Whole Genix S.L, Avenida Diagonal-640, Barcelona, Spain \\ ${ }^{3}$ Blood Genetics S.L, C. Verge de Guadalupe 18, Esplugas de Llobregat, Spain
}

\begin{abstract}
Alterations in the MET proto-oncogene, such as amplification or mutations causing exon 14 skipping, promote tumor growth, cellular transformation and invasion and are associated with poor prognosis in many types of cancers. There are several c-Met-targeted agents currently in clinical trials, highlighting the importance on developing accurate, efficient and sensitive technologies for the analysis. This short communication will provide an update on three of the most useful technologies for the detection of c-Met exon 14 skipping abnormalities, namely New Generation Sequencing (NGS), nCounter and qPCR
\end{abstract}

Keywords: Oncogene; Glioblastoma; Gene mutation; Next-generation sequencing

\section{Introduction}

The MET proto-oncogene is located in human chromosome 7 band $7 \mathrm{q} 21-\mathrm{q} 31$, includes 21 exons and 20 introns and encodes a tyrosine kinase receptor (RTK) [1]. The c-Met protein is mostly expressed by epithelial cells and binds with a high-affinity to its ligand, hepatocyte growth factor (HGF) [2,3]. HGF specific union to c-Met induces dimerization and autophosphorylation of the receptor, activating several downstream signalling pathways such as mitogen-activated protein kinase (MAPK), phosphatidylinositol 3-kinase (PI3K), V-Src avian sarcoma, viral oncogene homolog ( $\mathrm{Src})$, signal transducer and activator of transcription (STAT) and nuclear factor kappa-B (NFKB) $[3,4]$. Under normal physiological conditions, these pathways enhance tissue regeneration, wound healing, migration, invasion or apoptosis [4].

\section{Implication of c-Met in cancer}

Aberrant c-Met signalling is related to the progression of a wide variety of cancers such as liver, colon, gastric, breast, ovarian, pancreatic, prostate and lung tumours as well as some nervous system malignancies in particular, glioblastoma [5-8]. In tumor cells, this abnormal activation, which is directly associated with $M E T$ gene mutation, high gene amplification or protein overexpression, stimulates the signalling pathways mentioned above, leading to invasion, anti-apoptosis, cell transformation and metastasis $[6,7,9]$. Consequently, c-Met alterations are associated with poor patient prognosis $[7,9]$.

\section{MET exon 14 skipping}

MET exon 14 encodes part of the juxta-membrane region of the receptor, including the Y1003 residue, which constitutes the E3 ubiquitin ligase casitas B-lineage lymphoma (CBL) binding site for c-Met degradation $[9,10]$. In the past ten years, several studies have reported somatic mutations around the splice donor or acceptor sites of $M E T$ exon 14, inducing exon 14 skipping during RNA processing and to the deletion of the juxta membrane domain in the c-Met receptor $[1,11]$. As a result, a c-Met protein with oncogenic potential is expressed, leading to increased activation of downstream signalling pathways (Figure 1) $[12,13]$.
Currently, MET gene exon 14 skipping is considered as a potential driver mutation in a significant number of cancers, being lung adenocarcinomas (3-4\%) and other lung neoplasms (2.3\%) the most prevalent $[10,13]$. In addition, c-Met inhibitors such as crizotinib and cabozatinib have demonstrated clinical efficacy in patients with tumors harbouring MET skipping alterations. A better identification of these aberrations through emerging diagnostic tests may lead to a more precise selection of patients for c-Met targeted therapies [11,13].

\section{Methods for detecting MET mutations}

The development of cancer therapies targeted to specific driver mutations has revolutionized the treatment of some malignancies, such as non-small cell lung cancer (NSCLC). This precision medicine is based on an accurate identification of the driver alterations in the tumor tissue or in liquid biopsies [3].

Traditionally, the detection and quantification of RNA has been done using retro-transcription quantitative PCR (RT-Q-PCR) as a gold standard [14]. However, NanoString nCounter system has emerged as a new approach due to its highly accuracy, sensitivity and specificity for clinical studies and shorter turnaround time [15]. nCounter enables for multiplexed RNA digital quantification through the use of colorcoded molecular barcodes with less 100ng of total RNA and without amplification or generation of cDNA. More importantly, it can be used for the analysis of different types of samples even highly fragmented RNA from formalin-fixed paraffin-embedded tissue (FFPE). Moreover, nCounter allows the simultaneous evaluation of up 800 genes on total RNA. This platform is already in use in the clinical setting for

*Corresponding author: Dr. Cristian Tornador, Teresa Moretó Foundation, C. Verge de Guadalupe 18, Esplugas de Llobregat-08950, Spain, Tel: 34934453930 E-mail: cristian.tornador@ftmoreto.org

Received October 24, 2018; Accepted November 05, 2018; Published November 08, 2018

Citation: Martínez S, Tornador C (2018) Comparison of New Generation Sequencing (NGS), nCounter and Quantitative PCR (qPCR) Technologies for the Detection of MET Exon 14 Skipping Mutations. J Mol Genet Med 12: 375 doi:10.4172/1747-0862.1000375

Copyright: @2018 Martínez S, et al. This is an open-access article distributed under the terms of the Creative Commons Attribution License, which permits unrestricted use, distribution, and reproduction in any medium, provided the original author and source are credited 
Citation: Martínez S, Tornador C (2018) Comparison of New Generation Sequencing (NGS), nCounter and Quantitative PCR (qPCR) Technologies for the Detection of MET Exon 14 Skipping Mutations. J Mol Genet Med 12: 375 doi:10.4172/1747-0862.1000375

\section{Intron 13}

Intron 14

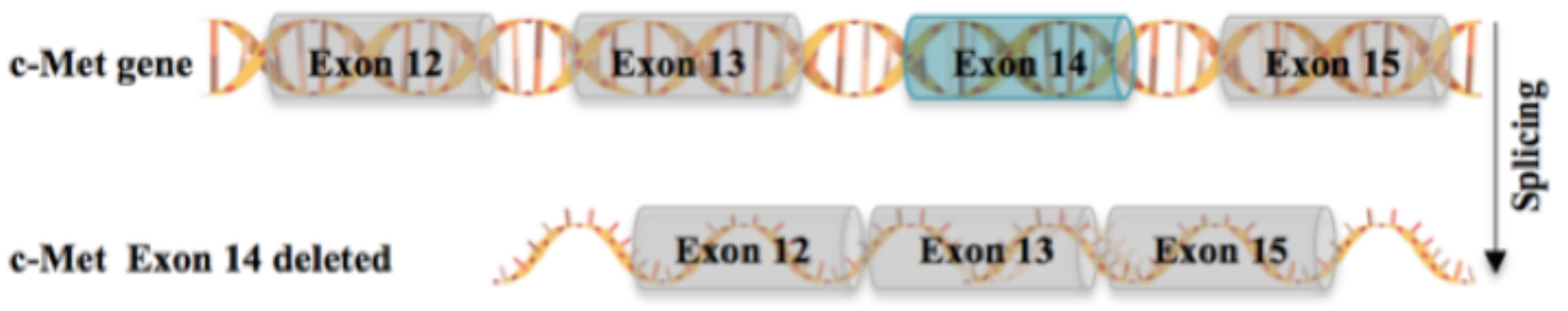

Figure 1: Splice site mutations can trigger the production of alternative RNA transcripts. The deletion of exon 14 blocks the degradation of c-Met.

\begin{tabular}{|l|l|}
\hline \multicolumn{1}{|c|}{ Ref Gene } & \multicolumn{1}{c|}{ Func.ref Gene } \\
\hline NM_000245: exon14:c, G3028A: p,D1010N & $\begin{array}{l}\text { Non-synonymous SNV, Splicing } \\
\text { - Last position exon }\end{array}$ \\
\hline $\begin{array}{l}\text { NM_001127500: exon14: c, G3082A: } \\
\text { p,D1028N }\end{array}$ & $\begin{array}{l}\text { Non-synonymous SNV, Splicing } \\
\text { - Last position exon }\end{array}$ \\
\hline NM_000245: exon14: c,3028 + 2T > C & Splicing \\
\hline NM_001127500: exon14: c,3028 + 2T > C & Splicing \\
\hline NM_001324402: exon14: c,G1798T: p,D600Y & Non-synonymous SNV \\
\hline NM_001324402: exon14: c,C1805T: p,S602F & Non-synonymous SNV \\
\hline NM_001324402: exon14: c,1969 + 1G > A & Splicing \\
\hline
\end{tabular}

Table 1: Detection of exon 14 mutations in samples from NSCLC patients using NGS analysed by our laboratory.

identification of relevant driver alterations in cancer patients, including MET exon 14 skipping [12,16].

Currently, Q-PCR or PCR followed by Sanger sequencing is also a well-established analytical methodology for identification of clinical mutations, showing sensitivities of $1 \%$ and $10 \%$, respectively [14]. Nevertheless, these two assays are target-specific, meaning that they can only detect the mutation they are designed for $[14,17]$. This is a disadvantage in the case of MET skipping, which can be originated by a variety of mutations on genomic DNA.

\section{Discussion}

Next-generation sequencing (NGS) is a cost-effective and highthroughput technology that is already replacing PCR-based assays in many clinical laboratories $[1,18]$. NGS can detect common and uncommon alterations, being able to simultaneously screen multiple mutations in several genes. In addition, NGS can identify novel genomic alterations that have not been identified before by PCR-based tests $[17,19]$. However, it requires qualified personnel to avoid false negative or false positive samples, which may occur as a result of the poor-quality samples, wrongful post-analytical data interpretation or lack of experience $[3,14]$.

In our laboratory, we have successfully used NGS for the detection of exon 14 abnormalities in clinical samples from NSCLC patients (Table 1). To be more precise, we generated our libraries with a great coverage using less than 10 ng of DNA.

\section{Conclusion}

PCR-based techniques where initially used for the detection of MET exon 14 skipping alterations, but new multiplexed approaches such as nCounter and NGS are currently replacing them. In fact, despite its limitations, NGS is emerging as the new standard platform for diagnostic testing in tumor samples. Further technological developments and new improvements in NGS analytical management will pave the way for a widespread use of NGS in the clinical setting.

\section{References}

1. Pasquini G, Giaccone G (2018) C-MET inhibitors for advanced non-small cell lung cancer. Expert Opin Investig Drugs 27: 363-375.

2. García-vilas JA, Medina MA (2018) Updates on the hepatocyte growth factor/cMet axis in hepatocellular carcinoma and its therapeutic implications. World J Gastroenterol 24: 3695-3708.

3. Gambella M, Palumbo A, Rocci A (2015) MET/HGF pathway in multiple myeloma: From diagnosis to targeted therapy? Expert Rev Mol Diagn 15: 881-893.

4. Bouattour M, Raymond E, Qin S, Cheng AL, Stammberger UZ, et al. (2018) Recent developments of c-Met as a therapeutic target in hepatocellular carcinoma. Hepatol 67: 1132-1149.

5. Lim YC, Kang HJ, Moon JH (2014) c-Met pathway promotes self-renewal and tumorigenecity of head and neck squamous cell carcinoma stem-like cell. Oral Oncol 50: 633-639.

6. Zhang $\mathrm{Y}$, Xia M, Jin K, Wang S, Wei H, et al. (2018) Function of the c-Met receptor tyrosine kinase in carcinogenesis and associated therapeutic opportunities. Mol Cancer 1: 1-14.

7. Marano L, Chiari R, Fabozzi A, Vita F, Boccardi V, et al. (2015) c-Met targeting in advanced gastric cancer: An open challenge. Cancer Letters 365: 30-36.

8. Anestis A, Zoi I, Karamouzis MV (2018) Current advances of targeting HGF/cMet pathway in gastric cancer. Mol Oncol 6: 247

9. Vuong HG, Ho ATN, Altibi AMA, Nakazawa T, Katoh R, et al. (2018) Clinicopathological implications of MET exon 14 mutations in non-small cell lung cancer - A systematic review and meta-analysis. Lung Cancer 123: 76-82.

10. Awad MM, Oxnard GR, Jackman DM, Savukoski DO, Hall D, et al. (2016) MET Exon 14 mutations in non - small-cell lung cancer is associated with advanced age and stage-dependent MET genomic amplification and c-Met overexpression. J Clin Oncol 34: 721 to 730.

11. Zheng D, Wang R, Ye T, Yu S, Hu H, et al. (2013) MET exon 14 skipping defines a unique molecular class of non-small cell lung cancer. Oncotarget 7 : 41691-41702.

12. Saigi M, McLeer-Florin A, Pros E, Nadal E, Brambilla E, et al. (2017) Genetic screening and molecular characterization of MET alterations in non-small cell lung cancer. Clin Transl Oncol 87: 122-129.

13. Mo H, Liu P (2017) Targeting MET in cancer therapy. Chronic Dis Transl Med 3: $148-153$.

14. Khodakov D, Wang C, Zhang DY (2016) Diagnostics based on nucleic acid sequence variant profiling: PCR, hybridization and NGS approaches. Adv Drug Deliv Rev 105: 3-19.

15. Kim S, Lee J, Hong ME, Do IG, Kang SY, et al. (2014) High-throughput sequencing and copy number variation detection using formalin fixed embedded tissue in metastatic gastric cancer. PLoS One 9: e111693.

16. Murat CDB, Rosa PWL, Fortes MAHZ, Corrêa L, Machado MCC, et al. (2015) 
Citation: Martínez S, Tornador C (2018) Comparison of New Generation Sequencing (NGS), nCounter and Quantitative PCR (qPCR) Technologies for the Detection of MET Exon 14 Skipping Mutations. J Mol Genet Med 12: 375 doi:10.4172/1747-0862.1000375

Page 3 of 3

Differential expression of genes encoding proteins of the HGF/MET system in insulinomas. Diabetol Metab Sydrome 7: 1-2.

17. Xu X, Yang Y, Li H, Chen Z, Jiang G, et al. (2016) Assessment of the clinical application of detecting EGFR, KRAS, PIK3CA and BRAF mutations in patients with non-small cell lung cancer using next-generation sequencing. Scandonavian J Clin Lab Investig 76: 386-392.

18. Cernomaz AT, Macovei IIM, Pavel I, Grigoriu C, Marinca M, et al. (2016)
Comparison of next generation sequencing, SNaPshot assay and realtime polymerase chain reaction for lung adenocarcinoma EGFR mutation assessment. Pulm Med 16: 1-2.

19. Sabari JK, Santini F, Bergagnini I, Lai WV, Arbour KC, et al. (2017) Changing the therapeutic landscape in non-small cell lung cancers: the evolution of comprehensive molecular profiling improves access to therapy. Curr Oncol Report 19: 1-2. 